BLS 35, No 1 2009. DOI: http://dx.doi.org/10.3765/bls.v35i1.3606

(published by the Berkeley Linguistics Society and the Linguistic Society of America)

\title{
Multidirectional Vowel Harmony in Esimbi
}

\author{
CRISTIN KALINOWSKI \\ University at Buffalo (SUNY)
}

\section{Introduction}

The theoretical literature on vowel harmony makes a distinction between stem-controlled and dominant systems. In the former, the stem is the source of the harmony, and vowels in affixes harmonize to the stem. In languages which are both prefixing and suffixing, harmony spreads linearly from the stem bidirectionally (right to left and left to right). The latter depends on a specific harmonizing feature, often present in an affix, which triggers harmony throughout the harmonic domain (Hulst and Weijer 1995). The distinction between these harmonic systems is the source. In stem-controlled harmony, the harmonic features spread from the stem, while in dominant harmony, the feature can spread from an affix vowel. Regardless of this distinction, however, both systems make use of a single source of harmony. While both of these types of harmony are well-attested, a language with multiple sources of harmony within the same harmonic domain is rare. In Esimbi (Southern Bantoid: Cameroon), the reduplicated progressive verbal paradigm exhibits both stem-controlled and prefix-controlled harmonic processes within the same domain. These two sources of harmony, the stem and the subject prefix, give rise to a vowel harmony system which is multidirectional, both linearly (left to right and right to left) and morphologically (stem-controlled and prefix-controlled).

Esimbi is spoken by 20,000 people in 11 villages of the Northwest Province of Cameroon, centered in the village of Benakuma. According to Ethnologue (Gordon 2005), the language is classified as Tivoid by virtue of lexical similarity (35\%) with other Tivoid languages. Both the Esimbi and other inhabitants of the province, however, report that the Esimbi people are "different" from other people in the area. Both their language and their social customs set them apart from their neighbors. One of the most unique aspects of the language is its vowel harmony.

Previous work on vowel harmony in Esimbi has situated the language typologically within the stem-controlled systems of harmony. The vowel harmony of nouns has been described by Stallcup (1980) and Hyman (1988), and the majority of the verbal paradigms exhibit the same harmonic processes as nouns. This 


\section{Cristin Kalinowski}

paper's contribution to the description of vowel harmony in Esimbi is the prefix-controlled harmony present in the reduplicated progressive paradigm, which effectively reclassifies the language in regards to the typology of known vowel harmony systems. Section 1 summarizes the two stem-controlled processes already described. Section 2 introduces prefix-controlled vowel harmony and describes the interaction between the three harmonic processes at work in the progressive paradigm. Section 3 suggests theoretical implications for vowel harmony based on the Esimbi data. It is not the goal of this paper to provide a solution which accounts for the new data. Rather, the present work is a description of the vowel harmony present in Esimbi and a brief explanation of the challenges it presents to the theoretical frameworks employed up to this point.

\section{Stem-Controlled Harmony}

Esimbi has a noun class system typical of Bantoid languages. There are fifteen fully productive noun classes, and concord is overtly marked throughout the noun phrase. Nouns are marked with a class prefix, and the verbal subject prefix agrees in class with the subject of the phrase. It is these subject and class prefixes which are the targets of stem-controlled vowel harmony.

There are two stem-controlled harmonic processes in Esimbi. The first is a diachronic process which affects the height of class prefixes, and occurs in all nouns and verbs. The second is a synchronic backness harmony which also targets both nouns and verbs, but is more selective in its distribution.

\subsection{Vowel Inventory and Height Harmony}

There are eight vowels in Esimbi, given in (1). While all vowels appear in prefixes, only high vowels $(i, ə, u)$ occur in noun and verb stems.

Vowel Inventory

\begin{tabular}{|c|c|c|c|}
\hline & front & central & back \\
\hline high & $\mathrm{i}$ & $\partial$ & $\mathrm{u}$ \\
\hline \multirow{2}{*}{ mid } & $\mathrm{e}$ & & $\mathrm{o}$ \\
\cline { 2 - 2 } & $\varepsilon$ & & $\partial$ \\
\hline \multirow{2}{*}{ low } & & $\mathrm{a}$ & \\
\hline
\end{tabular}

The atypical unequal distribution of prefix and stem vowels can be accounted for historically. Reconstructed forms show a more typical vowel distribution; only four vowels $(i, e, a, u)$ occurred in prefixes, while the entire range of vowels occurred in stems. Stallcup's explanation of the current distribution shows two stages, illustrated in (2). In the first stage, prefix vowels harmonized in height with stem vowels. Once stem height was expressed on the prefix vowels as a completely regular process, the stem vowels were systematically raised to high. The result is a system in which the underlying vowel height of the stem is syn- 


\section{Multidirectional Vowel Harmony in Esimbi}

chronically realized solely on the prefix. Table (2), adapted from Stallcup (1980), shows this process with three nouns from Class 3 . The first column shows the Proto-Bantu reconstructions of the noun stems, which are cognates of the Esimbi forms. In Pre-Esimbi, we see the addition of the Class 3 prefix $u$ - to noun stems of varying vowel height. In the height harmony stage, the prefix vowel is changed to agree in height with the vowel of the noun stem, while maintaining its own backness. In the last stage, the vowels of the stems are raised to [+high], leaving the prefix alone to realize the original height distinction.

Historical Height Harmony

\begin{tabular}{|l|l|l|l|l|}
\hline Class 3 Nouns & Proto-Bantu & Pre-Esimbi & Height Harmony & Stem Raising \\
\hline 'death' & $*$-ku & $*$ ú-kú & $* u ́-k u ́ ~$ & ú-kú \\
\hline 'tail' & $*$-keda & $*$ ú-kye & $*$ ó-kye & ó-kyi \\
\hline 'thigh' & $*$-nama & $*$ ú-nàmà & *ó-nàmà & ó-nòmò \\
\hline
\end{tabular}

Synchronically, the loss of vowel height has given rise to a large number of homophonous noun and verb stems. Since it is the height of the prefix vowel which disambiguates, bare noun stems do not occur. In the verbal paradigm, however, the imperative forms are realized as bare verb stems. Thus, the majority of imperatives are homophonous, and rely on context for disambiguation.

There are still four prefix vowels in Esimbi, but each vowel must now be able to exhibit the three-way height distinction which the stems lost. Table (3) shows the allophonic variation of these four vowels. The variant is chosen which matches the underlying height of the stem. A stem with a vowel that was historically high will select the highest vowel of the appropriate vowel set. Likewise, a stem that was historically mid will select the middle vowel and a historically low stem will select the lowest vowel. Note that the surface form of a prefix vowel is often ambiguous in terms of height. A surface $\varepsilon$, for instance, could be either the lowest realization of the $I$ - prefix or the middle realization of the $E$ - prefix.

\section{Prefix Vowel Heights}

\begin{tabular}{|l|l|l|l|}
\hline I- & E- & A- & U- \\
\hline i- & & & u- \\
\hline e- & e- & o- & o- \\
\hline e- & c- & o- & o- \\
\hline & a- & a- & \\
\hline
\end{tabular}

An example of prefixes disambiguating homophonous stems is given in (4) with the infinitive form of three verbs. The infinitive prefix is $k A$-, with allophones $k o$, $k s$, and $k a$. The underlying height of stems are indicated in all examples with a subscript $[\mathrm{H}],[\mathrm{M}]$, or $[\mathrm{L}]$. The imperative forms of these verbs shows the near 


\section{Cristin Kalinowski}

homophony of these three. Only the last one, 'stay', is further disambiguated by tone.

$$
\begin{array}{llll}
\text { ko-mu }_{[\mathrm{H}]} & \text { 'to drink' } & \mathrm{Mu} \text { ! } & \text { 'Drink!' } \\
\mathrm{k}-\mathrm{mu}_{[\mathrm{M}]} & \text { 'to go up' } & \mathrm{Mu} \text { ! } & \text { 'Go up!' } \\
\text { ka-mù } & \text { 'to stay' } & \mathrm{Mù!} & \text { 'Stay!' }
\end{array}
$$

\subsection{A- Harmony}

The second stem-controlled harmonic process targets prefixes with the $A$-vowel. When this vowel occurs with a stem that selects the middle vowel, the prefix vowel, $\rho$, harmonizes in backness with the stem. If the stem vowel is back or central $(\mathrm{u}, \curvearrowright)$, the prefix vowel is $\supset$. If the stem vowel is front $(i)$, the prefix vowel fronts to $\varepsilon$. This harmony, illustrated in (5), occurs in both nouns and verbs. The example uses the $k A$ - infinitive prefix. Notice that the prefix vowel is the corresponding $A$ - vowel $(o, o, a)$ except when the underlying stem vowel is mid-front. High and low allophones of this prefix vowel do not participate in this process.

\begin{tabular}{|c|c|c|c|}
\hline & front stem vowel & central stem vowel & back stem vowel \\
\hline high & ko-ri ${ }_{[\mathrm{H}]}$ 'eat' & & ko-mu $u_{[\mathrm{H}]}$ 'drink' \\
\hline mid & ke-bi ${ }_{[M]}$ 'boil' & ko-gbo $[\mathrm{M}]$ 'die' & ko-mu $[\mathrm{M}]$ 'go up' \\
\hline low & ka-tili $[\mathrm{L}]$ 'be slippery' & ka-təbə[L] 'grow' & ka-mu $[\mathrm{L}]$ 'stay' \\
\hline
\end{tabular}

Infinitives

\subsection{An Underspecification Approach}

The first theoretical work on Esimbi approached the data from the point-of-view of underspecification. In Hyman (1988), a feature system was introduced which posited two underlying prefix vowels, $I$ - and $U$-, and derived the other two prefix vowels from them by way of the $[+/-$ ATR] feature. $A$ - was described as a lowered variant of $U_{-}$, and $E$ - a lowered variant of $I-$. This allowed the possibility of a single surface form to be associated with two different sets of features, given in (6), adapted from Hyman (1988:265). This two-to-one mapping was considered necessary since there is significant overlap in the prefix allophones.

\begin{tabular}{|c|c|}
\hline [+high, -low, +ATR] & $\mathrm{i}, \partial, \mathrm{u}$ \\
\hline [+high, -low, -ATR] / [-high, -low, +ATR] & $\mathrm{e}, \mathrm{o}$ \\
\hline [-high, -low, -ATR] / [-high, +low, +ATR $]$ & $\varepsilon, \supset$ \\
\hline [-high, +low, -ATR] & $\mathrm{a}$ \\
\hline
\end{tabular}

(6) Vowel Features

Height was transferred from stem to prefix before vowels were fully specified, and any vowels which remained unspecified for height, namely stem vowels, 


\section{Multidirectional Vowel Harmony in Esimbi}

were assigned [+high] as a default. $A$ - harmony was described as a secondary process.

\subsection{An Optimality Theory Approach}

Height transfer was discussed in an Optimality Theory framework in Walker (1999). In the analysis, root faith is ranked higher than affix faith, allowing the height of the root to be realized instead of the height of the prefix. A licensing constraint accounts for the transfer of height to the prefix by stipulating that non-high root heights can only be realized on the first syllable of the word. These constraints, presented in (7) below, operate in tandem with an epenthetic [+high] feature and a requirement that features not be double-linked.

$$
\begin{aligned}
& \text { Constraint Ranking } \\
& \text { Faith: MAX-ROOT[height] }>\text { * }[- \text { high] }>>\text { MAX-AFFIX[height], DEP[+high] } \\
& \text { Licensing: LICENSE([-high], } \left.\sigma_{1}\right)>>\text { MAX-AFFIX[height], DEP[+high] } \\
& \text { Tautosyllabicity: TAUT-SYLL[height] }>>\text { DEP[+high] }
\end{aligned}
$$

While these constraints accounted for all of the noun-class data available at the time, they are based on the assumption that stem height must be realized somewhere in order to prevent homophony. The prediction that follows is that the first syllable of a word exhibits the full range of vowel height even if it is a bare stem. The existence of homophonous imperatives from (4) above, however, is evidence against this prediction.

\section{The Reduplicated Progressive Aspect}

While the two stem-controlled harmonic processes discussed in Section 1 occur systematically throughout Esimbi, prefix-controlled harmony is much smaller in scope. It occurs in the reduplicated progressive paradigm, where two prefixes co-occur. The progressive aspect in Esimbi is given in (8) and illustrated with the verb $k o-r i_{[\mathrm{H}]}$ 'eat' in (9). The leftmost morpheme is a subject prefix. It agrees with the subject either in person/number or in class. It is followed by a reduplication of the first syllable of the verb stem. Between the reduplicated syllable and the verb stem is what will be referred to as the "progressive vowel" (VPRG.), an epenthetic vowel which occurs only in this construction. The verb stem follows this progressive vowel. If the stem is monosyllabic, an extension in the form of $-n V$ is added, the $\mathrm{V}$ being identical to the stem vowel.

$$
\text { SUBJ PREFIX + REDUP + VPRG. }+ \text { stem }(+\mathrm{NV})
$$




\section{Cristin Kalinowski}

(9)

$$
\begin{aligned}
& \text { mi.rié.ri.ni } \\
& \text { mi- ri- } \quad \text { é- ri }{ }_{[\mathrm{H}]}
\end{aligned}
$$

\subsection{Subject Prefixes}

The subject prefix vowels are of two different types. Some are invariant for height, while others exhibit the three-way height distinction typical of prefixes. Subject prefixes for each person and class are given in (10). Variable prefix vowels are listed with a capital letter and invariant ones in lowercase. Only back vowels are of variable height, but not all back vowels participate in height harmony. For example, $2 \mathrm{sg} / \mathrm{pl} w u$ - and Class $12 \mathrm{ku}$ - are invariant back vowel prefixes. It is possible for subject prefixes in this construction to be invariant for height because it is the progressive vowel, as we shall see below, which obligatorily exhibits the three-way height distinction.

(10) Subject Prefixes

$\begin{array}{llll}\text { 1sg } & m i- & \text { Class 6a } & m U- \\ 1 \mathrm{pl} & s i- & \text { Class 8 } & m i- \\ \text { 2sg/pl } & w u- & \text { Class 9 } & i- \\ \text { 3sg } & U- & \text { Class 10 } & i- \\ \text { 3pl } & m ə- & \text { Class 12 } & k u- \\ \text { Class 1 } & U- & \text { Class 13 } & t i- \\ \text { Class 2 } & m U- & \text { Class 14 } & m U- \\ \text { Class 3 } & U- & \text { Class 18 } & m U- \\ \text { Class 5/7 } & k i- & \text { Class 19 } & s i- \\ \text { Class 6 } & U- & & \end{array}$

Examples (11) and (12) provide a contrast between variable and invariable prefixes. (11) uses the invariable second person prefix $w u$-, while (12) has the variable 3 SG prefix $U$-, with allophones $u, o$, and $\lrcorner$. The vowels under consideration are underlined in the examples.
wu. $. m(u) o ́ . m u[H] \cdot n u$
'You are drinking.'

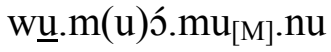
'You are going up.'
wu..m(u)á.mu $u_{[\mathrm{L}]} \cdot n u$
'You are staying.'
'He is drinking.'
o.m(u)ó.mu $u_{[\mathrm{M}]} \cdot \mathrm{nu}$
'He is going up.'
o.m(u)á.mu $u_{[L]} \cdot n u$
'He is staying.'

(12) ‥m(u)ó.mu $u_{[H]} \cdot n u$ 


\section{Multidirectional Vowel Harmony in Esimbi}

\subsection{Reduplicated Vowels}

The vowel of the reduplicated syllable, the second element of this construction, is often deleted or reduced by additional phonological processes. First, if this vowel is the central vowel, $ə$, it is deleted, as in (13).

$$
\begin{aligned}
& \text { mi.gbe.gbə.nə }
\end{aligned}
$$

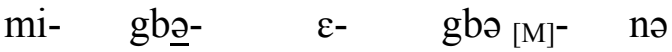

$$
\begin{aligned}
& \text { 1SG- die.REDUP-V.PRG- die- EXT } \\
& \text { 'I am dying.' }
\end{aligned}
$$

If the reduplicated vowel is of the same backness as the progressive vowel, it is either deleted or forms a diphthong, as shown in (14). These two possibilities are in free variation, though individual speakers are more or less consistent.

$$
\begin{aligned}
& \text { mi.biz.bi.ni. or mi.be.bi.ni } \\
& \text { mi- bí- } \varepsilon^{-} \quad b i_{[M]^{-}} \text {ni } \\
& \text { 1SG- boil.REDUP- V.PRG- boil- EXT } \\
& \text { 'I am boiling.' }
\end{aligned}
$$

Finally, when the reduplicated vowel is of the opposite backness as the progressive vowel, it forms a diphthong, as illustrated in (15).

$$
\begin{array}{ll}
\text { mi.zuz.zu.mu } & \\
\text { mi- } \quad \text { zu- } & \varepsilon-\quad \text { zumu }_{[M]} \\
\text { 1SG- dry.out.REDUP- } & \text { V.PRG- dry.out } \\
\text { 'I am drying out.' } &
\end{array}
$$

\subsection{The Progressive Vowel and Prefix-Controlled Harmony}

The progressive vowel is the most susceptible to harmonic processes. It belongs to one of the 'lower' vowel series, $E$ - or $A$-. That is, the highest vowel that appears is $e$ or $o$. Example (11), repeated below as (16), shows the stem-controlled height harmony of the progressive vowel. Since the second person prefix is invariant $(w u-)$, the progressive vowel is the only difference in this minimal triplet.

$$
\begin{aligned}
& \text { wu.m(u)ó. } \mathrm{mu}_{[\mathrm{H}]} \text {.nu } \quad \text { 'You are drinking.' } \\
& \text { wu.m(u). } \mathrm{mu}_{[\mathrm{M}]} \cdot \mathrm{nu} \quad \text { 'You are going up.' } \\
& \text { wu.m(u)á.mu }[\mathrm{L}] . \text { nu } \quad \text { 'You are staying.' }
\end{aligned}
$$

This vowel also participates in stem-controlled $A$ - harmony. As (17) shows, when the stem vowel is front and the underlying height is mid, the progressive vowel is $\varepsilon$ rather than 0 . 


\section{Cristin Kalinowski}

$$
\begin{aligned}
& \text { mi.ch(i)éc.chi.shi }{ }_{[\mathrm{M}]} \quad \text { 'I am teaching' } \\
& \text { wu.ch(i)É.chi.shi }{ }_{[\mathrm{M}]} \quad \text { 'You are teaching' } \\
& \text { u.ch(i)é.chi.shi }{ }_{[\mathrm{M}]} \quad \text { 'He is teaching' } \\
& \text { si.ch(i)é.chi.shi } \mathrm{i}_{[\mathrm{M}]} \quad \text { 'We are teaching' }
\end{aligned}
$$

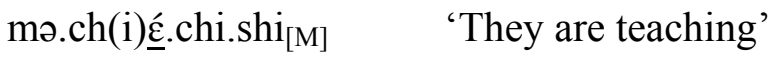

The progressive vowel is also the target of prefix-controlled backness harmony. If not overridden by $A$ - harmony, this vowel agrees in backness with the subject prefix. This can be seen in the examples in (18). A front prefix vowel occurs with a front progressive vowel, while a non-front prefix vowel ( 2 or back) occurs with a back progressive vowel. It must be the subject prefix which triggers this harmony, rather than the progressive vowel, as subject prefixes are invariant for backness.

$$
\begin{array}{ll}
\text { mi.r(i)e.ri.ni } & \text { 'I am eating' } \\
\text { wu.rio.ri.ni } & \text { 'You are eating' } \\
\text { u.rio.ri.ni } & \text { 'He is eating' } \\
\text { si.rie.ri.ni } & \text { 'We are eating' } \\
\text { mə.rio.ri.ni } & \text { 'They are eating' }
\end{array}
$$

The value of the progressive vowel is different from any of the prefix vowels in Esimbi. It is a lowered vowel, which rules out $U$ - or $I$-. It participates in $A$ harmony, however it is fronted regardless of height in the presence of a front subject prefix vowel. Since $A$ - only has a fronted mid allophone, the presence of a fronted high allophone discounts $A$ - as the underlying form. In fact, the only feature that this vowel has inherently is what Hyman (1988) would label [-ATR]. It has no underlying height, as the stem determines the height, and it has no underlying backness, as backness is determined either by the stem if it is mid-front ( $A$ - harmony) or by the subject prefix. It has been suggested that the progressive vowel is allophonic, either $E$ - or $A$ - depending on the backness of the subject prefix; however the selection of an underspecified allomorph based on the quality of the vowel of a different prefix is a rare, if even attested, phenomenon.

\section{Conclusions and Implications}

Vowel harmony in Esimbi involves three phonological processes. The first, transfer of underlying height from stem to prefix, is diachronically a vowel harmony process but synchronically best described in terms of feature transfer since the harmonizing height feature does not appear in the surface form of the stem. The second process, $A$ - harmony, falls into the domain of stem-controlled vowel harmony: a front vowel in the stem causes the mid prefix vowel to be fronted. However this process only affects prefix vowels belonging to the $A$ series. The same surface vowel, if an allophone of $U$-, is unaffected by harmony. The third harmony moves in the opposite direction, from left to right. The source 


\section{Multidirectional Vowel Harmony in Esimbi}

is the subject prefix, and it targets the non-stem "progressive vowel". These three harmonic processes converge on the progressive vowel in such a way that its height is determined by the stem, to its right, and its backness is determined either by the stem (if it is mid-front) or more commonly by the subject prefix to its left.

The challenges that the Esimbi data provide to a theoretical description are numerous. First, the underlying stem height is not always expressed. The imperative is a bare verb stem in which the underlying stem height is not realized. Second, vowel height is transferred to either just the progressive vowel, in the case of invariant subject prefixes, or to both the progressive vowel and the subject prefix vowel, in the case of variable prefixes. Third, the stem vowel determines the backness of the progressive vowel only if the stem vowel is front and underlyingly mid. Finally, the subject prefix determines the backness of the progressive vowel if the stem doesn't. This creates a system with a second source of harmony which spreads in the opposite linear direction (left to right). The theoretical descriptions provided for the noun system in Hyman (1988) and Walker (1999) adequately describe height transfer for the data that were available at the time; however neither of them account for the progressive verb data without modification. Future fieldwork on Esimbi will help to situate these data both in the grammar of Esimbi and in a broader typological framework of vowel harmony.

\section{References}

Gordon, Raymond G., Jr., ed. 2005. Ethnologue: Languages of the world, Fifteenth edition. Dallas, TX: SIL International. Online version: http://www.ethnologue.com/.

Hulst, H., and J. Weijer. 1995. Vowel harmony. In J. Goldsmith, ed., Handbook of phonological theory, 495-534. Oxford: Blackwell.

Hyman, Larry M. 1988. Underspecification and vowel height transfer in Esimbi. Phonology 5:255-273.

Stallcup, Kenneth L. 1980. Noun classes in Esimbi. In Larry M. Hyman, ed., Noun classes in the Grassfields Bantu borderland. Southern California Occasional Papers in Linguistics 8:139-153.

Walker, Rachel 1999. Esimbi vowel height shift: Implications for faith and markedness. Ms., University of Southern California.

Cristin Kalinowski

University at Buffalo, State University of New York

Department of Linguistics

609 Baldy Hall

Buffalo, NY 14260

cmk1@buffalo.edu 